\title{
K Prime
}

National Cancer Institute

\section{Source}

National Cancer Institute. K Prime. NCI Thesaurus. Code C52564.

A dimensionless value that refers to the molar concentrations of chemical reactants and products under standard conditions. 